Eur J Clin Chem Clin Biochem

1995; 33:337-342

(c) 1995 Walter de Gruyter \& Co.

Berlin $\cdot$ New York

\title{
Reference Limits of Apolipoprotein A-I and Apolipoprotein B Using an IFCC ${ }^{1}$ ) Standardized Immunonephelometric Method
}

\author{
By Josiane Steinmetz ${ }^{1}$, Pierrette Tarallo ${ }^{1}$, Blandine Fournier $^{1}$, Emile Caces $^{2}$ and Gerard Siest ${ }^{1}$ \\ 1 Centre de Médecine Préventive, URA CNRS 597, Vandouvre-Les-Nancy, France \\ 1 Institut Régional pour la Santé, La Riche, France
}

(Received November 29, 1994/March 31, 1995)

Summary: An important collaborative study organized by the IFCC enabled the selection of international reference materials and the standardization of commercially available methods by the use of common calibrators.

In this paper, we report the reference limits of apolipoprotein A-I and apolipoprotein B in a selected healthy French population. The apolipoprotein measurements were performed on BNA Behring using reagents and protocols supplied by the manufacturer: the standard sera were calibrated using the IFCC-WHO reference preparations (SP1 and SP3). In addition, the apolipoprotein B protocol was modified by the addition of a supplementary reagent to reduce the interference by lipaemic samples on immunonephelometric measurement. In a sample of 115 random serum samples, there was a decrease in mean concentration between non-standardized and standardized methods: $-4.8 \%$ for apolipoprotein A-I and $-4.7 \%$ for apolipoprotein B. The reference limits for apolipoprotein A-I are unaffected by gender between 4 and 14 years, thereafter vary with age and gender until 40 years and with gender alone between 40 and 60 years. For apolipoprotein B, the variation with gender is only significant between 30 and 49 years.

\section{Introduction}

Apolipoproteins A-I and B play a major physiological role in HDL and LDL metabolism, respectively: they bind and transport lipids, serve as structural components of lipoproteins and direct their metabolism through reaction with tissue receptors and the activation or inhibition of enzyme reactions $(1-2)$.

Although most prospective epidemiological studies had essentially reported HDL and LDL cholesterol values, it was demonstrated that apolipoprotein A-I and B concentrations might provide a better indicator of coronary artery disease risk than lipoprotein cholesterol $(3-5)$.

The development of apolipoprotein A-I and B measurement in clinical laboratories has been limited due to the

1) Abbreviations

IFCC: International Federation of Clinical Chemistry

WHO: World Health Organisation

SFBC: Société Française de Biologie Clinique lack of comparability of results obtained by different centers (6). An international survey suggested that the major source of variation resulted from the use of different calibration materials (7). A collaborative study supported by the IFCC was implemented in 1989 (8-9) to solve this problem. The aim of this multistep project was to evaluate and select reference materials suitable for consideration as international reference materials and to standardize commercially available methods by a common accuracy-based calibration. Two reference preparations with determined values were selected and certified as international reference materials by the IFCC (10-12).

SP1 has been approved by the World Health Organisation (WHO) as "International Reference Material for Apolipoprotein A-I" on the basis of the results of the final study (12). WHO has more recently also endorsed SP3-07 as the WHO International Reference Material for apolipoprotein $\mathrm{B}$. 
This paper reports apolipoprotein A-I and B reference values obtained in a selected healthy French population admitted for a periodic health examination in two Centers for Preventive Medicine. Apolipoprotein A-I and B concentrations were determined by an immunonephelometric method performed on the Behring Nephelometer Analyzer (BNA) using detergent (Thesit) in each protocol as proposed by the manufacturer. The apolipoprotein standard sera had been calibrated by the manufacturer using the IFCC-WHO reference preparations (SPI and SP3) for apolipoprotein A-I and apolipoprotein B. In addition, we have evaluated the differences between results obtained with these new protocols and with the old non-standardized immunonephelometric methods by measuring apolipoprotein A-I and apolipoprotein B on 115 non-selected serum samples with the same BNA analytical system.

\section{Patients and Methods}

Patients

To determine reference values, we selected 1271 healthy subjects (633 men and 638 women) aged 4 to 60 years who attended for a periodic health examination two Centres for Preventive Medicine (Vandœuvre-Les-Nancy and La Riche, Tours) during April and May 1993.

The exclusion criteria, based on our experience and on data from the literature (14-16) were:

- Subject with a value below the 5th and above the 95th percentiles by age and sex for: cholesterol, triacylglycerols, glucose, creatinine, urea, bilirubin, uric acid concentrations, $\gamma$-glutamyltransferase, alanine aminotransferase, aspartate aminotransferase, alkaline phosphatase activities, red blood cell counts

- Subjects with the following diseases noted either on the health questionnaire or at clinical examination: atherosclerosis, myocardial infarction, hyperthyroidism, hypothyroidism, renal insufficiency, nephrotic syndrome, chronic or acute hepatitis, liver cancer, anaemia with the presence of target red cells

- Pregnant women

- Subjects taking drugs and oral contraceptives or substitutive oestroprogestatives

- Subjects with weight $\pm 20 \%$ of the ideal weight according to the Lorenz formula

- Subjects smoking more than 10 cigarettes per day (or equivalent)

- Subjects reporting a consumption of more than $22 \mathrm{~g}$ of alcohol per day for women and more than $44 \mathrm{~g}$ per day for men

- Subjects following a specific diet

The partition criteria were age and sex.

The comparison of measurement protocols for the two apolipoproteins was performed in the Vandœuvre lès Nancy laboratory on 115 serum samples from a non selected population with triacylglycerol concentrations between 0.31 and $3.45 \mathrm{mmol} / \mathrm{l}$ (mean $=1.22$ $\mathrm{mmol} / \mathrm{l})$.

\section{Methods}

Blood samples were collected in tubes without any anticoagulant but with separator gel (Vacutainer, Becton-Dickinson, Le Pont de Claix, France). Blood specimens were obtained by venipuncture from the antecubital vein from fasting, supine subjects between 08.00 and $09.00 \mathrm{~h}$. Sera stored at $4{ }^{\circ} \mathrm{C}$ were analysed one day after blood collection; the delay allowed the application of exclusion criteria. Turbid, haemolysed or icteric samples were discarded. Apolipoprotein measurements were performed on the BNA Behring instrument, with reagents (antibodies, calibrator, control sera) manufactured by Behring Diagnostic (Rueil Malmaison, France). The same batches of all the reagents were used in the two laboratories. The methodologies for apolipoprotein A-I and B were as follows:

\begin{tabular}{lll}
\hline & $\begin{array}{l}\text { Apolipo- } \\
\text { protein A-I }\end{array}$ & $\begin{array}{l}\text { Apolipo- } \\
\text { protein B }\end{array}$ \\
\hline Sample volume $(\mu \mathrm{l})$ & 10 & 30 \\
Sample dilution & $1 / 20$ & $1 / 20$ \\
Minimum dilution & $1 / 20$ & $1 / 20$ \\
Reagent 1 volume & 40 Apolipoprotein & 40 Apolipoprotein \\
$\quad(\mu \mathrm{l})$ & A-I antibodies & B antibodies \\
Reagent 2 volume & 10 Supl R. "P"/ & 10 Supl R. "P"/ \\
$\quad(\mu l)$ & SRP & SRP \\
Reaction buffer & 80 N-reaction & 80 N-reaction \\
$\quad$ volume (1) & buffer & buffer \\
Reaction buffer & 80 & 70 \\
$\quad$ volume (2) & & \\
Measuring time (min) & 6 fixed time & 6 fixed time \\
Standard & N-apolipoprotein & N-apolipoprotein \\
& standard & standard \\
No. of standard & 6 & 5 \\
$\quad$ points & & \\
First dilution 1: & 5.0 & 5.0 \\
Deviation allowed \% & 5.0 & 5.0 \\
Validity (days) & 7 & 7 \\
Concentration unit & g/l & g/l \\
\hline
\end{tabular}

The apolipoprotein A-I and B concentrations in calibrators were determined by comparison, with the IFCC-WHO reference preparations, SP1 for apolipoprotein A-I and SP3 for apolipoprotein B.

The within-run variation was tested on fresh pools of sera at two concentrations - the coefficients of variation were respectively $1.5 \%($ mean $=1.08 \mathrm{~g} / \mathrm{l})$ and $2.5 \%$ (mean $=1.57 \mathrm{~g} / \mathrm{l})$ for apolipoprotein A-I. They were $1 \%($ mean $=1.19 \mathrm{~g} / \mathrm{l}$ ) and $1.42 \%$ (mean $=1.25 \mathrm{~g} / \mathrm{l})$ for apolipoprotein B.

The day-to-day reproducibility was estimated by using control serum and a frozen pool of sera. The coefficients of variation were $5.0 \%($ mean $=1.26 \mathrm{~g} / \mathrm{l})$ and $4.1 \%$ (mean $=1.64 \mathrm{~g} / \mathrm{l})$ for apolipoprotein $\mathrm{A}-\mathrm{I}$, and $4.0 \%$ (mean $=0.97 \mathrm{~g} / \mathrm{l}$ ) and $3.6 \%$ (mean $=1.25$ $\mathrm{g} / \mathrm{l})$ for apolipoprotein $\mathrm{B}$.

The old protocols, proposed previously by manufacturers (no detergent for apolipoprotein B measuring and standard sera non calibrated on IFCC reference material), were used in the same way for the analytical comparison.

\section{Statistical analysis}

Analysis of variance was used to test whether the mean apolipoprotein A-I and apolipoprotein B concentrations differed between the two recruitement centers (after adjustment for age and sex). The Gaussian distribution of apolipoproteins A-I and B was tested for each sex and age group by the Anderson-Darling statistic, and 
reference limits were estimated by a parametric method. Using a new statistical approach (17) we have calculated reference limits in homogeneous subgroups by combining different age and sex classes (by a Student's test). If, for the two subgroups, the ratio of the standard deviation is below 1.5 and there is no significant difference between the mean, then they may be combined.

\section{Results}

\section{Analytical comparison}

The comparison of a standardized with a non-standardized methodology has shown that the mean apolipoprotein A concentration decreased from $1.65 \mathrm{~g} / 1$ to $1.57 \mathrm{~g} / 1$ (tab. 1). The differences varied from $-9.5 \%$ to $+1.4 \%$ depending on the sample, with an average difference corresponding to $4.8 \%(\mathrm{p}<=0.0005)$.

For apolipoprotein $\mathrm{B}$, the decrease corresponded to an average difference of $4.7 \%$ (tab. 1). It is important to note that for some samples with triacylglycerolaemia over $2.30 \mathrm{mmol} / 1$ the decrease varies between $10 \%$ and $23 \%$. On the other hand, an increase of $19 \%$ is observed in a serum with a triacylglycerol concentration of 0.38 $\mathrm{mmol} / \mathrm{l}$.

\section{Determination of reference values}

As the distribution of apolipoprotein A-I and B concentrations were not statistically different in the two refer-

Tab. 1 Comparison of apolipoprotein A-I and apolipoprotein B concentrations determined by standardized or non-standardized protocols $(n=115$ serum samples)

\begin{tabular}{|c|c|c|}
\hline \multicolumn{3}{|l|}{ Apolipoprotein A-I } \\
\hline & $\begin{array}{l}\text { Non-standardized } \\
\text { protocol }(x)\end{array}$ & $\begin{array}{l}\text { Standardized } \\
\text { protocol }(y)\end{array}$ \\
\hline Mean $(g / l)$ & 1.65 & 1.57 \\
\hline $\begin{array}{l}\text { Standard } \\
\text { deviation }(\mathrm{g} / \mathrm{l})\end{array}$ & 0.25 & 0.24 \\
\hline $\begin{array}{l}\text { Difference mean } \\
(\mathrm{t} \text { test } \\
\mathrm{p}<=0.0005)\end{array}$ & \multicolumn{2}{|c|}{$-4.79 \%(\max :+1.54 \%, \min :-9.50 \%)$} \\
\hline Regression equation & \multicolumn{2}{|l|}{$y=0.92 x+0.043$} \\
\hline \multicolumn{3}{|l|}{ Apolipoprotein B } \\
\hline & $\begin{array}{l}\text { Non-standardized } \\
\text { protocol }(x)\end{array}$ & $\begin{array}{l}\text { Standardized } \\
\text { protocol }(y)\end{array}$ \\
\hline Mean & 1.32 & 1.25 \\
\hline $\begin{array}{l}\text { Standard } \\
\text { deviation }(\mathrm{g} / \mathrm{l})\end{array}$ & 0.20 & 0.17 \\
\hline $\begin{array}{l}\text { Difference mean } \\
(t \text { test } \\
p<=0.0005)\end{array}$ & \multicolumn{2}{|c|}{$-4.69 \%(\max :+19.5 \%, \min :-22.6 \%)$} \\
\hline Regression equation & \multicolumn{2}{|l|}{$y=0.69 x+0.33$} \\
\hline
\end{tabular}

ence populations selected at Vandœuvre-Les-Nancy and Tours, the results were combined.

Tables 2 and 3 present the apolipoprotein A-I and B concentration percentiles, by sex and age class. The median apolipoprotein A-I concentrations varied with age. In males, apolipoprotein A-I concentrations decreased from $1.51 \mathrm{~g} / 1$ at $4-14$ years to $1.39 \mathrm{~g} / 1$ at $15-19$ years, followed by a slight increase to $1.56 \mathrm{~g} / 1$ at $50-59$ years.

In females, the median values remained constant ( 1.48 $\mathrm{g} / \mathrm{l})$ until age 19 , and increased in adults to $1.72 \mathrm{~g} / \mathrm{l}$ at 50-59 years. Except for children at age 14, females had higher values than males, the differences ranging from 7 to $12 \%$ according to age.

The increase of apolipoprotein B concentration with age in males and in females was only significant after 20 years of age. For the age group less than 20 years, the median values varied from 0.74 to $0.77 \mathrm{~g} / 1$ in males and from 0.76 to $0.80 \mathrm{~g} / 1$ in females. In the adult population, a steady increase was observed for the median in both sexes with age reaching $1.06 \mathrm{~g} / \mathrm{l}$ in males and $1.01 \mathrm{~g} / \mathrm{l}$ in females.

We tested whether there was a difference in the mean and standard deviation of apolipoproteins A-I and B by sex and age class. The absence of statistically significant differences enabled the presentation of reference limits for homogeneous groups (tab. 4).

\section{Discussion}

To minimize differences in apolipoprotein measurements between laboratories and methods, a standardization program, involving common reference materials was needed. A collaborative study was initiated by the Committee on Apolipoproteins of the IFCC; twenty five commercial laboratories and 3 research laboratories participated (8). The aim of this project was to calibrate all commercially available apolipoprotein A-I and apolipoprotein B test kits using serum pools previously standardized against primary reference materials. After evaluation and selection of two candidate reference materials, SP1 for apolipoprotein A-I and SP3 for apolipoprotein $B$, the third phase of the international study was to directly validate the selected reference material in the different systems, transfer the target values to the inhouse calibrators and validate the comparability of the data among different systems $(11,12)$.

In the present work, reference limits for apolipoproteins A-I and B in a sample of healthy subjects were established for the first time with standardized methods using standards calibrated with IFCC-WHO ${ }^{1}$ ) reference materials. In addition, the methodology for apolipoprotein $B$ 
Tab. 2 Reference values for apolipoprotein A-I $(g / l)$, given as percentiles

\begin{tabular}{|c|c|c|c|c|c|c|c|c|c|c|c|c|}
\hline \multicolumn{7}{|l|}{ Men } & \multicolumn{6}{|c|}{ Women } \\
\hline $\begin{array}{l}\text { Age } \\
\text { (years) }\end{array}$ & $\mathrm{N}$ & $2.5 \%$ & $5 \%$ & $50 \%$ & $95 \%$ & $97.5 \%$ & $N$ & $2.5 \%$ & $5 \%$ & $50 \%$ & $95 \%$ & $97.5 \%$ \\
\hline $4-9$ & 67 & 1.14 & 1.20 & 1.51 & 1.59 & 2.05 & 69 & 1.17 & 1.27 & 1.47 & 1.81 & 1.87 \\
\hline $10-14$ & 99 & 1.12 & 1.17 & 1.51 & 1.92 & 1.95 & 110 & 1.14 & 1.17 & 1.48 & 1.78 & 1.82 \\
\hline $15-19$ & 91 & 1.04 & 1.09 & 1.39 & 1.63 & 1.67 & 97 & 1.11 & 1.17 & 1.47 & 1.84 & 1.94 \\
\hline $20-29$ & 92 & 1.02 & 1.12 & 1.44 & 1.93 & 1.95 & 77 & 1.16 & 1.24 & 1.63 & 2.01 & 2.09 \\
\hline $30-39$ & 104 & 1.11 & 1.17 & 1.49 & 1.89 & 1.95 & 96 & 1.21 & 1.28 & 1.60 & 1.92 & 1.99 \\
\hline $40-49$ & 92 & 1.15 & 1.24 & 1.54 & 1.92 & 1.97 & 97 & 1.19 & 1.27 & 1.66 & 2.05 & 2.12 \\
\hline $59-59$ & 88 & 1.11 & 1.20 & 1.56 & 1.99 & 2.08 & 47 & 1.30 & 1.37 & 1.72 & 2.10 & 2.14 \\
\hline
\end{tabular}

Tab. 3 Reference values for apolipoprotein B (g/l), given as percentiles

\begin{tabular}{|c|c|c|c|c|c|c|c|c|c|c|c|c|}
\hline \multicolumn{7}{|l|}{ Men } & \multicolumn{6}{|c|}{ Women } \\
\hline $\begin{array}{l}\text { Age } \\
\text { (years) }\end{array}$ & $\mathrm{N}$ & $2.5 \%$ & $5 \%$ & $50 \%$ & $95 \%$ & $97.5 \%$ & $N$ & $2.5 \%$ & $5 \%$ & $50 \%$ & $95 \%$ & $97.5 \%$ \\
\hline $4-9$ & 67 & 0.40 & 0.51 & 0.77 & 1.02 & 1.12 & 69 & 0.51 & 0.54 & 0.80 & 1.08 & 1.10 \\
\hline $10-14$ & 99 & 0.40 & 0.49 & 0.74 & 0.95 & 0.99 & 110 & 0.46 & 0.49 & 0.76 & 0.99 & 1.05 \\
\hline $15-19$ & 91 & 0.46 & 0.50 & 0.74 & 1.02 & 1.04 & 97 & 0.45 & 0.50 & 0.80 & 1.09 & 1.15 \\
\hline $20-29$ & 92. & 0.54 & 0.59 & 0.82 & 1.18 & 1.22 & 77 & 0.44 & 0.50 & 0.84 & 1.17 & 1.24 \\
\hline $30-39$ & $104^{\circ}$ & 0.58 & 0.63 & 0.94 & 1.35 & 1.41 & 96 & 0.54 & 0.59 & 0.86 & 1.13 & 1.18 \\
\hline $40-49$ & 92 & 0.53 & 0.62 & 1.00 & 1.25 & 1.29 & 97 & 0.56 & 0.62 & 0.90 & 1.19 & 1.24 \\
\hline $50-59$ & 88 & 0.64 & 0.74 & 1.06 & 1.40 & 1.42 & 47 & 0.45 & 0.78 & 1.01 & 1.25 & 1.27 \\
\hline
\end{tabular}

Tab. 4 Reference limits for apolipoprotein A-I and B (g/l) (2.5 and 97.5 th percentiles, $n=$ number of subjects)

\begin{tabular}{|c|c|c|}
\hline \multicolumn{3}{|c|}{ Apolipoprotein A-I } \\
\hline $\begin{array}{l}\text { Age } \\
\text { (years) }\end{array}$ & Men & Women \\
\hline $4-14$ & \multicolumn{2}{|c|}{$1.11-1.90(n=345)$} \\
\hline $15-19$ & $1.04-1.67(n=91)$ & $1.11-1.94(n=97)$ \\
\hline $20-39$ & $1.05-1.95(n=196)$ & $1.22-2.08(n=173)$ \\
\hline $40-49$ & $1.15-1.97(n=92)$ & $1.19-2.12(\mathrm{n}=97)$ \\
\hline$>50$ & $1.11-2.04(n=88)$ & $1.30-2.14(\mathrm{n}=47)$ \\
\hline \multicolumn{3}{|c|}{ Apolipoprotein B } \\
\hline $\begin{array}{l}\text { Age } \\
\text { (years) }\end{array}$ & Men & Women \\
\hline $\begin{array}{r}4-19 \\
20-29\end{array}$ & \multirow{2}{*}{\multicolumn{2}{|c|}{$\begin{array}{l}0.45-1.08(\mathrm{n}=533) \\
0.51-1.23(\mathrm{n}=169) \\
=196) \quad 0.55-1.21 \quad(\mathrm{n}=193) \\
0.68-1.40(\mathrm{n}=135)\end{array}$}} \\
\hline $\begin{array}{r}30-49 \\
>50\end{array}$ & & \\
\hline
\end{tabular}

measurement was modified by the manufacturer in order to eliminate interference from triacylglycerol-rich lipoproteins and sample turbidity as has been mentioned elsewhere (13). However, addition of a detergent tends to increase low results.

Information on sources of biological, pathological and pharmacological variations are now well documented for apolipoproteins (14) and permitted us to select "a priori" a population according to well-defined criteria following the strategy recommended by IFCC and $\left.\mathrm{SFBC}^{1}\right)(15,16)$.

To exclude subjects with disease status which might modify apolipoprotein concentrations, we considered serum constituents (such as cholesterol, triacylglycerol, glucose, uric acid, bilirubin, etc ...), with a value below the 5th and above the 95th percentiles of the distribution in our population to be pathological. In addition, responses in the health questionnaire and the results of clinical examination were taken into account.

Subjects treated with drugs on a regular basis or the day before sampling, were excluded due to the specific effects of some drugs (such as hyperlipidaemic drugs, aspirin ${ }^{\circledR}$ or anticonvulsants) on blood constituents and because treatment implies the presence of pathology (18, 19).

Amongst the factors of biological variation that we have taken into account as exclusion criteria in women, pregnancy is the most important: at term, apolipoprotein A$I$ and B values may increase by more than $30 \%$ (20).

Others factors may have different effects on apolipoprotein A-I as compared to apolipoprotein B. For example, excess weight has no influence on apolipoprotein A concentration $(19,21)$ while it is highly correlated with a 
large increase in apolipoprotein B: $34 \%$ in men and $20 \%$ in women $(19,21-26)$. Alcohol consumption does not affect apolipoprotein B concentration but it produces an increase in apolipoprotein A-I concentration dependent on the quantity of alcohol ingested. Chronic alcohol consumption of more than $100 \mathrm{~g} /$ day can increase apolipoprotein A-I concentration by $15-20 \%(21-24)$. Tobacco consumption has opposite effects on the two apolipoproteins with a decrease in apolipoprotein A-I of about $15 \%(19,21,25,26)$ and an increase in apolipoprotein $B$ between 11 and $20 \%(19,27)$.

It is well known that nutritional influences play important roles in modifying blood lipids in a healthy population as well as in subjects with metabolic diseases. Thus a diet rich in poly-unsaturated fatty acids leads to low apolipoprotein A-I $(-19 \%)$ and apolipoprotein B $(-25 \%)$ concentrations (28). These influences have been taken into consideration in selecting the reference population for the definition of the reference values for apolipoproteins A-I and B presented in this paper. The standardization of apolipoprotein A-I and B measurements enables the comparison of results so that unique cut-off values can be defined and treated patients can be followed whatever the methodology used. Reference values presented in this work are the first obtained following the standardization of calibrators on WHOIFCC reference materials. Similar studies are necessary following other standardized methods.

\section{Acknowledgements}

We thank Dr Isabel Beucler (chairwoman of ARCOL standardization working group) and $\operatorname{Dr} A$. Legrand (chairman of SFBC lipid and lipoprotein standardization working group) for their critical comments.

The Behring reagents used in this study were kindly provided by Behring-France.

\section{References}

1. Naito HF. The clinical significance of apolipoprotein measurements. J Clin Immunoassay 1986; 9:11-20.

2. Brewer HB, Gregg RE, Hueg JM, Fojo SS. Apolipoproteins and lipoproteins in human plasma: an overview. Clin Chem 1988; 34:B4-B8.

3. Avogaro P, Cazzolato G, Bittolo Bon G, Quincy GB. Are apolipoproteins better discriminators than lipids for atherosclerosis? Lancet 1979; 1:901-3.

4. Debaker G, Rosseneu M, Deslypere JP. Discriminative value of lipids and apolipoproteins in coronary heart disease. Atherosclerosis 1982; 42:197-203.

5. Reinhart RA, Gani K, Amdt MR, Broste SK. Apolipoprotein $\mathrm{AI}$ and $\mathrm{B}$ as predictor of angiographically defined coronary artery disease. Arch Intern Med 1990; 150:1629-33.

6. Smith SJ, Henderson LO, Hannon WH, Cooper GR. Effects of analytical methods and lyophilized sera as measurements of apolipoproteins $\mathrm{AI}$ and $\mathrm{B}$ - an international survey. Clin Chem 1990; 36:290-6.

7. Smith SJ, Cooper GR, Henderson LO. An international collaborative study on standardization of apolipoproteins A-I and B. Part I. Evaluation of a lyophilized candidate reference and calibration material. Clin Chem 1987; 33:2240-9.

8. Marcovina SM, Albers JJ. Standardization of the immunochemical determination of apolipoproteins A-I and B. A report on the International Federation of Clinical Chemistry meeting on standardization of apolipoproteins A-I and B measurements (basis for future consensus) Vienna Austria, April 18-19, 1989. Clin Chem 1989; 35:2009-15.

9. Marcovina SM, Albers JJ, Dati F, Ledue TB, Ritchie RF. International Federation of Clinical Chemistry Standardization project for measurement of apolipoproteins AI and B. Clin Chem 1991; 37:1676-82.

10. Albers JJ, Marcovina SM, Kennedy H. International Federation of Clinical Chemistry Standardization project for measurements of apolipoproteins $\mathrm{AI}$ and B. II. Evaluation and selection of candidate reference material. Clin Chem 1992; 38:658-62.

11. Marcovina SM, Albers JJ, Henderson LO, Hannon WH. International Federation of Clinical Chemistry. Standardization project for measurement of apolipoprotein AI and B. III. Comparability of apolipoprotein AI values by use of international reference material. Clin Chem 1993; 39:773-81.
12. Marcovina SM, Albers JJ, Kennedy H, Mei JV, Henderson LO, Hannon WH. International Federation of Clinical Chemistry. Standardization project for measurement of apolipoprotein AI and B. IV. Comparability of apolipoprotein B values by use of international reference material. Clin Chem 1994; 40:586-92.

13. Walmsley TA, Grant S, George PM. Effect of plasma triglyceride concentrations on the accuracy of immunoturbidimetric assays of apolipoprotein B. Clin Chem 1991; 37:748-53.

14. Steinmetz J, Parsy D. Apolipoprotein AI et B. In: Siest G, Henny J, Schiele F, editors. References en biologie clinique. Paris. Elsevier 1990:107-21.

15. International Federation of Clinical Chemistry and International Committee for Standardization in Haematology. Approved recommendation on the theory of reference values. The concept of reference values. J Clin Chem Clin Biochem 1987; 25:337-42.

16. Siest G, Henny F, Schiele F, Gueguen R. Le concept des valeurs de référence. Ses relations avec les sources de variations des examens de laboratoire. In: Siest G, Henny J, Schiele F, editors. References en biologie clinique. Paris Elsevier 1990:23-42.

17. Harris EK, Boyd JC. On dividing reference data into subgroups to produce separate reference ranges. Clin Chem 1990; 36:265-70.

18. Luoma PV, Myllyla VV, Sotaniemi EA, Hokkanen TEJ. Plasma HDL cholesterol and growth hormone in epileptics treated with anticonvulsants. Acta Pharmacol Toxicol 1980; 47:249-54.

19. Cuvelier I. Apolipoproteins. In: References values and their biological variation, Foster City: Biomedical Publication 1985:119-29.

20. Montes A, Walden CE, Knopp RH, Cheung M, Chapman MR, Albers JJ. Physiologic and supraphysiologic increases in lipoprotein lipids and apolipoproteins in late pregnancy and postpartum. Arteriosclerosis 1984; 4:407-17.

21. Donahue RP, Orchard T, Stein EA, Kuler LH. Apolipoproteins $\mathrm{AI}, \mathrm{AII}$ and $\mathrm{B}$ in young adults. Associations with CHD risk factors. The Beaver County Experience. J Chron Dis 1986; 39:823-30. 
22. Cushman P, Barboriak J, Kalbfleisch J. Alcohol: high density lipoproteins, apolipoproteins. Alcohol Clin Exp Res 1986; 10:154-7.

23. Hartung GH, Reeves RS, Foreyt JP, Patsch W, Gotto AM. Effect of alcohol intake and exercise on plasma high-density lipoprotein cholesterol subfractions and apolipoprotein A-I in women. Am J Cardiol 1986; 58:148-51.

24. Masarei JRL, Puddey IB, Rouse IL, Lynch WJ, Vandongen R, Beilin LJ. Effects of alcohol consumption on serum lipoprotein-lipid and apolipoprotein concentrations. Results from an intervention study in healthy subjects. Atherosclerosis 1986; 60:79-87.

25. Craig WY, Palomaki GE, Haddow JE. Cigarette smoking and serum lipid and lipoprotein concentrations: an analysis of published data. Br Med J 1989; 298:784-8.

26. Haffner SM, Applebaum-Bowden D, Wahl PW, Hoover JJ, Warnick GR, Albers JJ, Hazzard WR. Epidemiological correlates of HDL subfractions, apolipoproteins A-I, A-II and D and lecithin cholesterol acyltransferase: Effects of smoking, alcohol and adiposity. Arteriosclerosis 1985; 5:169-77.

27. Caces E. Lemaure S, Vol S, Bagrel A, Tichet J, Boulard P. Apolipoprotein B: facteurs de variation et intérêt en médecine préventive. Proceeding of the Biologie Prospective, 5 e Colloque International de Pont-à-Mousson. Paris: Masson, 1983:723-6.

28. Vega GL, Groszek E, Wolf R, Grundy SM. Influence of polyunsaturated fats on the composition of plasma lipoproteins and apolipoproteins. J Lipid Res 1982; 23:811-22.

Josiane Steinmetz

Centre de Médecine Préventive URA CNRS

2, Avenue du Doyen Jacques Parisot F-54501 Vandœuvre les Nancy France 